\title{
Analysis of the variables influencing inter-area oscillations in the future Great Britain power system
}

DOI:

10.1049/cp.2019.0072

\section{Document Version}

Accepted author manuscript

Link to publication record in Manchester Research Explorer

\section{Citation for published version (APA):}

Asvapoositkul, S., \& Preece, R. (2019). Analysis of the variables influencing inter-area oscillations in the future Great Britain power system. In 15th IET International Conference on AC and DC Power Transmission (ACDC 2019) (pp. 72 (7 pp.)-72 (7 pp.)) https://doi.org/10.1049/cp.2019.0072

\section{Published in:}

15th IET International Conference on AC and DC Power Transmission (ACDC 2019)

\section{Citing this paper}

Please note that where the full-text provided on Manchester Research Explorer is the Author Accepted Manuscript or Proof version this may differ from the final Published version. If citing, it is advised that you check and use the publisher's definitive version.

\section{General rights}

Copyright and moral rights for the publications made accessible in the Research Explorer are retained by the authors and/or other copyright owners and it is a condition of accessing publications that users recognise and abide by the legal requirements associated with these rights.

\section{Takedown policy}

If you believe that this document breaches copyright please refer to the University of Manchester's Takedown Procedures [http://man.ac.uk/04Y6Bo] or contact uml.scholarlycommunications@manchester.ac.uk providing relevant details, so we can investigate your claim.

\section{OPEN ACCESS}




\title{
Analysis of the variables influencing inter-area oscillations in the future Great Britain power system
}

\author{
Surat Asvapoositkul, Robin Preece \\ School of Electrical and Electronic Engineering, The University of Manchester, Manchester, M13 9PL, U.K. \\ Email: surat.asvapoositkul@postgrad.manchester.ac.uk,robin.preece@manchester.ac.uk
}

Keywords: Correlation analysis, Inter-area oscillations, Network topology, Proxy variables, Small-signal stability.

\begin{abstract}
The integration of power electronics (PE) interfaced resources in electrical power systems has been growing continuously. In future power systems, PE-interfaced devices, including renewable energy resources (RES) and High Voltage Direct Current (HVDC) technologies, are going to play a significant role in providing electrical energy. Therefore, the study of power system stability in mixed AC/DC networks is of critical importance. A significant number of wind and HVDC technologies will be connected to the Great Britain (GB) network by 2030 , which makes the network an interesting study into the stability of mixed AC/DC networks with high numbers of PE-interfaced sources. In this paper, a reducedorder model of the future GB network is developed and used as a study case to explore the factors influencing the damping of an inter-area oscillation. The system variables are measured and a new measure, the centre of inertia (COI) electrical distance, is developed based on graph theory concepts to quantify changes in network topology. Then, correlation analysis is performed between these indices and the damping ratios of an inter-area oscillation. The results show that the new index, COI electrical distance, has a strong correlation with the damping of inter-area oscillation under changes in the network topology, which can be used for quick identification of potentially problematic operational scenarios.
\end{abstract}

\section{Introduction}

Non-synchronous sources, such as RES and HVDC systems, have been connected to power systems in increasing numbers. The amount of energy provided by RES, particularly wind generation, is continuously growing. According to statistical data, the global installed capacity of wind generation increased $10.78 \%$ in 2017, compared to 2016. In the United Kingdom (UK), the total installed capacity of wind generation increased $29 \%$ over a year in 2017 [1]. Besides a significant increase in wind generation, HVDC interconnections have been increasingly integrated into power systems to provide greater transmission capacity from other systems and increase market trading. The global installed capacity of HVDC interconnectors was approximately $270 \mathrm{GW}$ in 2016 and it is expected to reach $540 \mathrm{GW}$ by 2025 [2]. In the UK, total installed capacity of HVDC interconnectors and embedded links will be approximately $24.6 \mathrm{GW}$ by 2030 [3], equal to or even exceeding the minimum transmission system load.

Due to an increase in a number of PE-interfaced devices connected to power systems, the stability of mixed AC/DC grids needs investigation [4]. However, such a study is not typically conducted on systems with a large number of both multi-infeed HVDC and wind generation. As mentioned previously, the GB network will consist of a high level of wind generation and HVDC connections by 2030. Additionally, an inter-area oscillation between Scotland and England was detected in late 1970s [5]. This oscillation still exists due to the longitudinal structure of the network. Therefore, the GB network itself is a strong candidate case study for researchers exploring the impacts of nonsynchronous sources on power system stability, especially small-signal stability study. In this paper, a reduced-order model of the future (2030) GB network is developed in order to investigate the variables influencing damping of the critical inter-area oscillation.

Analysis of this study network will be used to identify steady state network characteristics that can be used as proxy variables of system stability - providing a reliable indication of stability without the need to run full stability analysis. The electrical distance between groups of oscillating generators is suggested as a potential proxy variable for inter-area oscillations since it is known that the damping of inter-area modes vary when the topology changes. Graph theory is introduced as a tool to quantify the network topology. The study of graphs and networks has been conducted in many interdisciplinary applications such as mathematics, computer science, physics, biology and economics [6]-[8]. In graph theory, a graph or network is a set of vertices (or nodes, or points) connected to each other by edges (or lines) [8]. This is obviously analogous to electrical power systems in which substations (nodes) are connected through power lines (edges) to provide power transfer between different areas. In this study, a selection of system variables is measured. COI electrical distance is developed and calculated based on one of the quantitative measures in graph theory. Spearman's rank correlation coefficient is calculated in order to identify the strength of linear relationship between these indices and damping of the inter-area oscillation. The main contributions of this research are summarised as follows:

- A reduced-order model of future GB system has been developed as a study case of a mixed AC/DC network.

- A new measure, the COI electrical distance, has been developed based on graph theory. Then, system 
variables are measured and COI electrical distance is calculated under various operating scenarios.

- Correlation analysis has been performed between the measured variables and damping ratios of the interarea mode in order to identify proxy identifiers of the inter-area mode damping.

\section{Modelling of future Great Britain network}

This section presents the process of modelling the future GB system for both steady state and dynamic simulation. The assumptions made during the design process are discussed.

\subsection{Steady state model of the future GB network}

The steady state model of the future GB system, used in this research, has been developed based on 29-bus GB system originally created by the University of Strathclyde (UoS) [9]. The boundaries of 29 areas are drawn based on two assumptions:

1. Firstly, each boundary is selected based on transmission system boundaries provided in Electricity Ten Year Statement (ETYS) [10].

2. Secondly, the transmission lines lying across the boundaries are compared with the transmission line data in the UoS model. The boundary is selected if it has similar transmission line data. If the transmission lines in the previous model cannot be identified, a boundary lying in the middle between two nodes in the right figure of Figure 1 is selected.

The resulting boundaries for the 29 areas used in this research are illustrated in Figure 1.

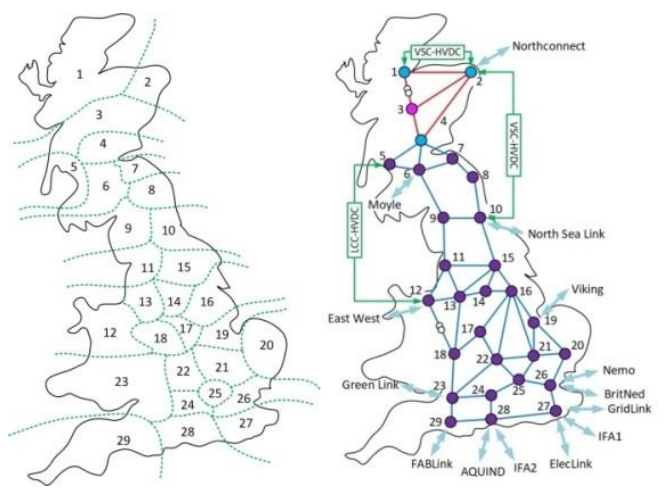

Figure 1: Boundaries for 29-bus GB network (left) and 29-bus model of future GB network (right)

Generating units and loads, provided in ETYS, are aggregated into 29 groups based on the areas in Figure 1 (left). The generating data is obtained from existing contracts that generators hold with National Grid and the demand data is forecasted and submitted by Distribution Network Operators (DNOs) [11]. Shunt devices operating at $132 \mathrm{kV}$ and above are selected in Scotland while the shunt elements operating at only $400 \mathrm{kV}$ are chosen in England. This assumption has been made because the lowest voltage level represented in the model in Scotland is $132 \mathrm{kV}$ and in England is $400 \mathrm{kV}$ (based on the UoS model).
The operating conditions of the system are calculated by using Optimal Power Flow (OPF) and Power Flow (PF) analysis. The System Non-Synchronous Penetration (SNSP) ratio is employed to determine the amount of nonsynchronous sources in the system. The calculation of SNSP is expressed as (1).

$$
\mathrm{SNSP}=\frac{\sum_{i=1}^{n} P_{\text {wind }}+\sum_{i=1}^{m} P_{H V D C, \text { import }}}{P_{\text {load }}+\sum_{i=1}^{p} P_{H V D C, \text { export }}}
$$

In (1), $P_{\text {wind }}$ is the active power generated from wind power plants. $P_{H V D C, \text { import }}$ and $P_{H V D C \text {,export }}$ are imported and exported active power through HVDC interconnections, $P_{\text {load }}$ is the total system active power load, and $n, m$ and $p$ are the number of wind power plants, imported-power HVDC, and exported-power HVDC sites respectively. The process of calculating the operating condition is described below. The flow chart of this process is in the Appendix.

- The amount of power dispatched by wind generation and the system demand are specified. The total power from HVDC connections is calculated in order to meet the desired SNSP.

- The OPF is performed using MATPOWER [12]

- The power flowing through embedded HVDC links is set to two-thirds of parallel AC lines. This applies to tie lines for Western and Eastern links (between Scotland and England) and AC lines between nodes 1 and 2 for the Caithness Moray HVDC line.

- The OPF is run once more to identify which generators should be shut down. The generators that operate under $30 \%$ of their ratings will be considered as uneconomic and shut down for this operational scenario.

- The power flow is simulated to identify the power factor of which generators need to be improved. The acceptable range of power factor can be found in [13]. Local shunt devices are adjusted in order to improve the power factor of synchronous generators.

- The power flow is simulated once again and the result is exported in order to set the operating condition of the system in PowerFactory.

It should be noted that the power generated from synchronous generations is dispatched based on merit order dispatch in OPF. The merit order dispatch from the cheapest to the most expensive is nuclear, hydro, CCGT, coal and OCGT respectively [14].

\subsection{Dynamic model of the future GB network}

After obtaining the steady state model, the dynamic models of electrical devices in the network are developed for studies of small-signal and transient stability. The transient dynamic models of generating units are selected from [13]. The control systems of synchronous generators are selected based on IEEE recommendations [15], [16]. The excitation systems used in this study are DC1A and ST1A. The ST1A excitation system is employed in nuclear power plants while the DC1A excitation system is installed in the remaining synchronous generators in the system. 
Three types of governor control systems are installed at the synchronous generators, including GAST, HYGOV and TGOV1. The governor control is selected based on the turbine of the synchronous generators. Therefore, GAST is used in CCGT and OCGT power plants. HYGOV is installed in hydro power plants and TGOV1 is installed in nuclear and coal power plants. The summary of generator control, both excitation and governor systems, is presented in the Appendix.

Two types of wind turbines are implemented in this study, double-fed induction generator (DFIG) and fully rated converter. The Western Electricity Coordinating Council (WECC) generic models for both types of wind generation are used in this research to represent the dynamic models of wind generation [17]. An assumption has been made that wind generation installed in the GB network before 2016 is considered as DFIG while any wind generation that is installed after 2016 is considered as fully rated converter. This assumption has been made because significant amount of off-shore wind generation is expected to be connected to the grid through fully rated converter wind turbines [18]. The dynamic model of HVDC has been neglected in this study though this is a priority for future model development. Thus, all HVDC connections are modelled as static (and possibly negative) loads.

\section{Quantitative measure for network topology}

It has been observed that changes in network topology have a significant impact on the damping of inter-area oscillations [19]. However, there is no standard numerical index used in power systems research that can be used to quantify such variations (e.g. line outages). Graph theory can provide several candidate measures, such as degree distribution, characteristic path length, clustering coefficient and centrality. In this research, the 29-bus GB network is considered as a graph. A new measure, the COI electrical distance $\left(d_{C O I}\right)$, is developed based on characteristic path length (CPL). The calculation of this measure is the summation of shortest path, existing between existing nodes in an entire system as shown in (2).

$$
\mathrm{CPL}=\frac{1}{n(n-1)} \sum_{\substack{\forall i, j \\ i \neq j}} d_{i j}
$$

In (2), $d_{i j}$ is the shortest distance between nodes $i$ and $j$ and $n$ is the number of nodes in the graph [20]. Since an inter-area oscillation is a main focus in developing of the COI electrical distance, the GB network is separated into two areas, Scotland and England (with generators grouped following modal participation analysis). The COI electrical distance is developed based on the following assumptions:

- The node pairs are the combination between nodes 110 in Scotland and nodes 11-29 in England, as illustrated in the right figure of Figure 1.

- An electrical distance between each node pair is calculated, as in [21]. The distance in (2) is replaced by the electrical distance in COI electrical distance.
- Since it is known that the damping of inter-area modes is also affected by the system inertia, each node pair is weighted by the inertia and rating of synchronous generators connected at the nodes.

- The denominator is neglected as the number of nodes in the system remains unchanged.

Based on the assumption above, $d_{C O I}$ can be calculated by using (3). $H_{i}$ and $H_{j}$ are the inertia constants of the synchronous generators connected to nodes $i$ and $j$ respectively. $S_{i}$ and $S_{j}$ are the ratings of the synchronous generators connected to nodes $i$ and $j . n_{i}$ and $n_{j}$ are the number of synchronous generators connected to nodes $i$ and $j . Z_{i j}$ is the electrical distance, as defined in [21], between nodes $i$ and $j$. Finally, $G_{a}$ and $G_{b}$ represent sets of synchronous generators oscillating against each other, Scotland and England in this study.

$$
d_{C O I}=\frac{\sum_{i \in G_{a}, j \in G_{b}} H_{i} n_{i} S_{i} H_{j} n_{j} S_{j} Z_{i j}}{\sum_{i \in G_{a}, j \in G_{b}} H_{i} n_{i} S_{i} H_{j} n_{j} S_{j}}
$$

The COI electrical distance is calculated and additional system variables - SNSP ratio, total system load and total power from wind generation - are recorded in order to determine the strength of the relationships between these indices and the damping of the inter-area oscillation.

\section{Statistical dependence between two variables}

Statistical dependence determines the strength of the relationship between two random variables. Two variables are statistically independent when changing the value of one of the variables has no impact on the variation of the other variable. On the other hand, two variables are dependent if the changing value of one variable leads to variations of the other [22]. Methods for correlation analysis, such as Pearson's and Spearman's correlations, have been widely used in order to numerically determine the dependency between variables.

\section{Spearman's rank correlation coefficient}

Pearson's and Spearman's correlations coefficients have been commonly used to determine the strength of statistical dependency [23]. Unlike Pearson's correlation coefficient, there are no underlying assumptions, such as normal distribution of variables, that need to be made when calculating Spearman's correlation coefficients [23]. Therefore, Spearman's correlation is selected as the measure of statistical dependence employed throughout this research. Spearman's correlation coefficient or Spearman's rho $\left(r_{s}\right)$ is defined in (4).

$$
r_{s}=1-\frac{6 \sum_{i=1}^{n} D_{i}^{2}}{n\left(n^{2}-1\right)}
$$

In (4), $D_{i}$ is the difference between the ranks of sample valuepairs and $n$ is the number of data sample value-pairs. The correlation coefficient is in the range from -1 to 1 . The closer the value of $r_{s}$ to these extreme values, the stronger the dependency and the relationship. 


\section{Identification of potential proxy variables for inter-area oscillations}

Before identifying influencing variables on damping of an inter-area oscillation, the operating conditions of the network are varied in order to generate hundreds of cases with different operating scenarios and damping ratios of the interarea oscillation. The SNSP is set at $30 \%$ for base case scenario. Power generated from wind generation is set at $35 \%$ of total installed capacity of wind generation and the system load is set at maximum total demand for the base case. Then, different cases with variations in the detailed system parameters, as shown in Table 1, have been investigated.

\begin{tabular}{ccccc}
\hline Case & SNSP & $P_{\text {wind }}$ & $P_{\text {load }}$ & N-1 \\
\hline 1 & $\checkmark$ & & & \\
2 & & $\checkmark$ & & \\
3 & & & $\checkmark$ & \\
4 & & & & $\checkmark$ \\
5 & $\checkmark$ & $\checkmark$ & $\checkmark$ & \\
6 & $\checkmark$ & $\checkmark$ & $\checkmark$ & $\checkmark$ \\
\hline
\end{tabular}

Table 1: Case studies with different variations

In Table 1, each column represents the variation of that particular parameter from base case. SNSP column shows a variation in SNSP from base case scenario. $P_{\text {wind }}$ is a variation in power generated from wind generations. $P_{\text {load }}$ is a variation in the system load and $\mathrm{N}-1$ represents tripping of one transmission line at a time. One-dimensional variations are represented in cases 1 to 4 while multi-dimensional variations are investigated in cases 5 and 6 .

\subsection{Case 1: SNSP variations}

In the first case, SNSP ratios are uniformly randomly selected in the range of $\pm 10 \%$ from base case. Although the power generated from wind generation and system load are fixed at the same values as they are set in the base case, the power from both synchronous generators and HVDC interconnections can still change in order to meet the desired SNSP. The plot between damping ratios of the inter-area oscillation and the SNSP ratios is illustrated in Figure 2.

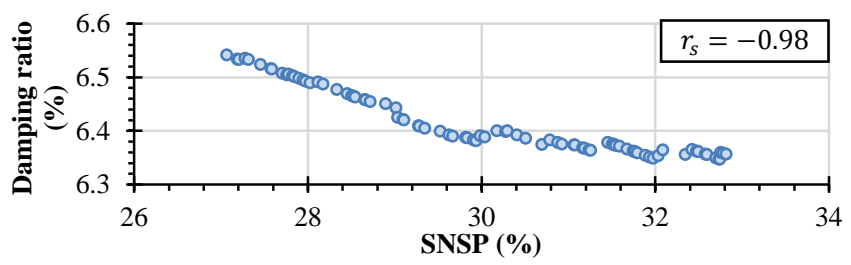

Figure 2: Variations in damping ratio of the inter-area oscillation when the SNSP varies.

The Spearman's rho is equal to -0.98 . It means there is a very strong negative correlation between damping of the inter-area oscillation and the SNSP ratio. It can be explained by the fact that when the SNSP reduces, the total electrical power generated by synchronous generators increases, resulting in an increase in the number of generators online. However, the average loading of each synchronous generator reduces, and the damping torque provided from synchronous generators, therefore, increases.

\subsection{Case 2: Wind variations}

In the second case, the power generated by wind sources is randomly varied. The power generated from each wind generation is uniformly randomly dispatched in the range of $\pm 10 \%$ from base case while the power dispatched from synchronous generators and HVDC connections are adjusted in order to maintain the SNSP at the desired value and meet the system load. The plot of damping ratios of the inter-area oscillation and variations in total power generated from wind generation is shown as Figure 3.

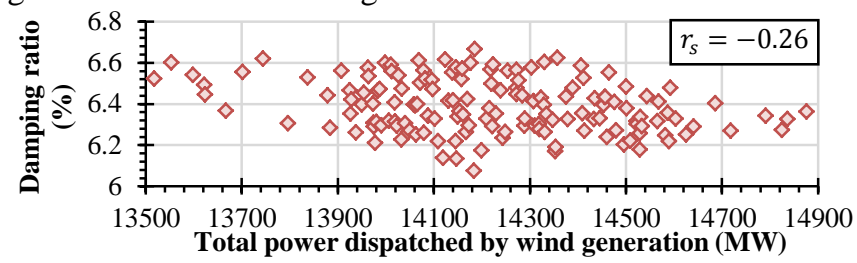

Figure 3: Variations in damping ratio of the inter-area oscillation when the power generated from wind farms varies.

The plot above shows that there is a relatively weak negative correlation between damping ratios of the inter-area oscillation and the total wind power. The Spearman's rho between these two variables is -0.26 . The weak correlation can be explained by the fact that the location of injected power from wind generation affects the damping of the interarea mode. If the power from wind generation is injected at locations that have a large load, the number of synchronous generators will decrease as they are displaced by the wind sources. On the other hand, if the power from wind generation is injected at locations that already have very low load, the power will be exported from HVDC systems.

\subsection{Case 3: System load variations}

In the third case, the load values at each connection point (both active and reactive), are uniformly randomly chosen in the range of $\pm 10 \%$ from base case. Both SNSP ratio and power generated from wind power plants are fixed at their base case values. Similar to the previous cases, the power dispatched from synchronous generators and HVDC connections are adjustable according to the dispatch model.

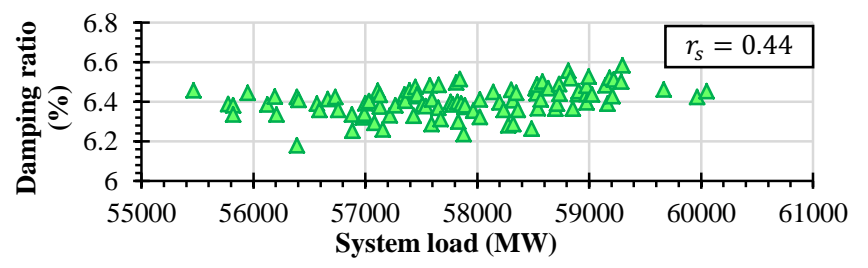

Figure 4: Variations in damping ratio of the inter-area oscillation when the system load varies.

As illustrated in Figure 4, the Spearman's rho between the variations in system loads and damping of inter-area mode is only 0.44 . It can be interpreted that there is only a moderate correlation between the damping of the inter-area mode and variations in total system load. 


\subsection{Case 4: $\mathrm{N}-1$ variations}

For the forth case, influencing variables on damping of an inter-area oscillation under changing in network structure is investigated. The operating condition of the system is set to the same value as in the base case. However, each transmission line in the network is set to out of service one at a time, resulting in variations in the network topology. In this case, $d_{C O I}$ is plotted against the damping of the inter-area mode as in Figure 5.

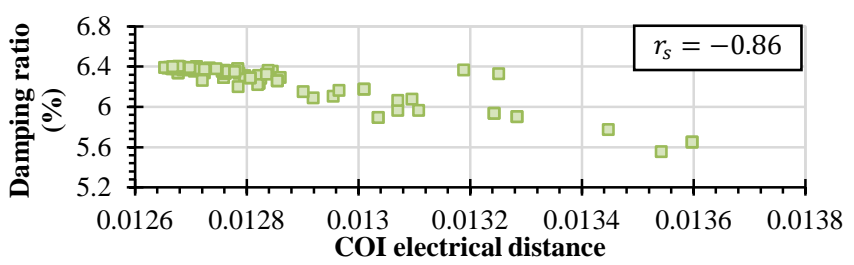

Figure 5: Variations in damping ratio of the inter-area oscillation when a transmission line is tripped one by one.

There is a very strong negative correlation between COI electrical distance and damping of the inter-area oscillation, with the correlation coefficient at -0.86 , as shown in Figure 5. The mode shape of the inter-area oscillation has been investigated. It has been found that when the COI electrical distance becomes larger, the speed of hydro generators in Scotland deviates from the group of generators in Scotland and the damping of inter-area mode decreases.

\subsection{Case 5: SNSP, wind and load variations}

In real power systems, it is uncommon to have only one variation in the whole system. Therefore, in this case, all variations from cases 1 to 3 are applied to the system simultaneously without any change in network topology. The plots representing the correlation between damping ratios of the inter-area mode and SNSP as well as damping of the inter-area mode and COI electrical distance are illustrated in Figure 6 and 7 respectively.

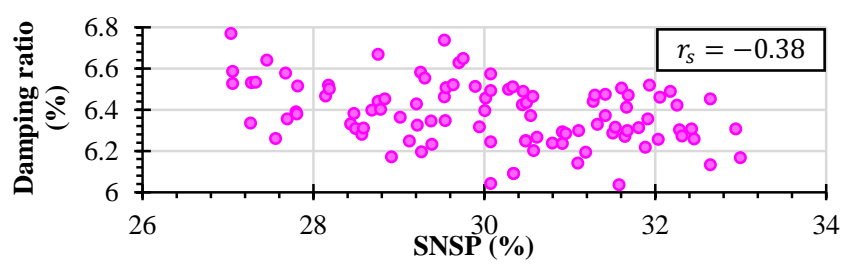

Figure 6: Variations in SNSP against damping ratios of the inter-area mode for case 4.

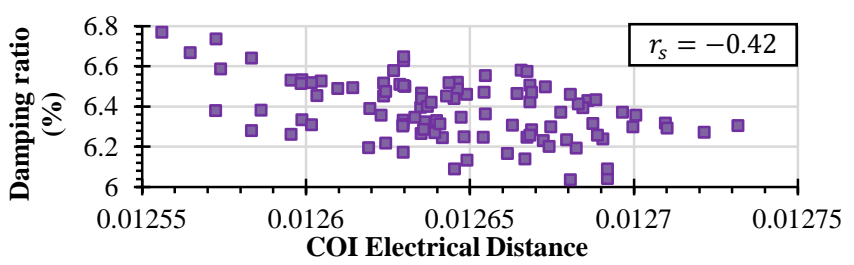

Figure 7: Variations in COI electrical distance against damping ratios of the inter-area mode for case 4 .

By comparing between Figure 2 and Figure 6, it is apparent that the correlation between SNSP and damping of the inter- area mode decreases significantly. When all variations are applied to the system, the correlation coefficient between SNSP and damping of the inter-area mode is only -0.38 , representing moderate negative correlation. The correlation between COI electrical distance and the damping of the interarea mode is calculated from the data in Figure 7, with only -0.42 in Spearman's rho. As explained in case 1, when the SNSP reduces, the number of synchronous generators increases, resulting in an increase in damping torque in the system. However, with all variations included, a reduction in SNSP may correspond to an increase in the power from synchronous generators, a reduction in the amount of wind generation, or even an increase in the load. As a consequence, the correlation with the damping of the inter-area mode is significantly reduced.

\subsection{Case 6: SNSP, wind, load and N-1 variations}

In the last case, the variations, including SNSP, power generated from wind generations and the system load, are applied all at once. Additionally, one transmission line in the system is randomly selected as being out of service in each simulation, representing changes in network topology. Therefore, in this case, the potential proxy variables are investigated under the variations in both system parameters and network topology.

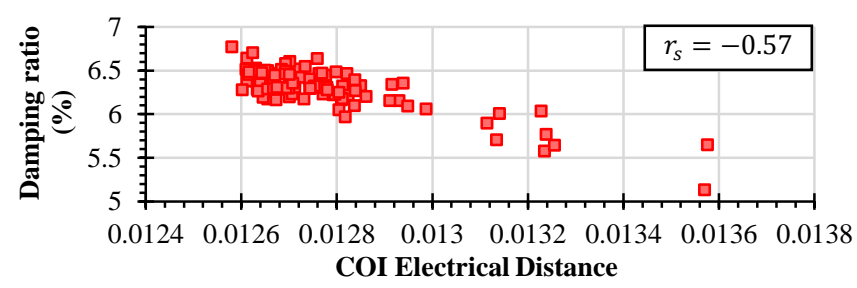

Figure 8: Variations in COI electrical distance against damping ratios of the inter-area mode for case 5.

As shown in Figures 6 and 7, the correlation coefficient reduces obviously when all variations are imposed to the system simultaneously. However, by comparing the plots in Figures 5, 7 and 8, the COI electrical distance is able to maintain a stronger correlation with damping of the inter-area mode when there are changes in network structure. Although the correlation coefficient decreases when all variations are applied to the system, the COI electrical distance still shows a moderate correlation with the damping of the inter-area mode, with -0.57 of Spearman's rho as shown in Figure 8. By comparing to case 5, it is apparent that the variations in network topology have a large impact on the damping of the inter-area mode. Furthermore, COI electrical distance shows the strongest relationship when network variations are included.

\section{Conclusion}

A reduced-order model of the future $2030 \mathrm{~GB}$ system has been developed in this study in order to represent a mixed AC/DC network with a significant number of PE-interfaced sources such as wind generations and HVDC connections. Different variations have been applied to the network in order 
to identify the variables influencing damping of inter-area oscillations. In the case of one-dimensional variation without any change in network topology (cases 1 to 3 ) it is evident that the SNSP shows very strong negative correlations with damping of the inter-area oscillation. This is explained by the fact that when the SNSP is decreases, the number of synchronous generators increases as the total electrical power generated by synchronous generators increases. However, the average loading of each synchronous generator decreases, leading to an increase in damping torque in the system provided from synchronous generators. Consequently, the damping of the inter-area mode increases. Regarding variations in wind generation, the location of wind generation has a large impact on the correlation with the damping of the inter-area mode. The number of synchronous generators reduces if the power from wind generation is injected to the area with a large load. However, the power will be exported from HVDC connections if the power from wind generation is injected to area with low amount of active power load, changing the oscillation damping.

The COI electrical distance is developed based on CPL to numerically quantify topology changes. By comparing the study cases including topology changes, it is obvious that there is a strong relationship between the damping of an interarea mode and COI electrical distance. As a result, this index can be a potential candidate for predicting the changes in damping of inter-area oscillations when there is a variation in network topology. In the future work, the impact of dynamic model of HVDC systems on inter-area oscillations will be investigated in more detail. Furthermore, different statistical and machine learning approaches will be investigated to build a prediction model for the damping of inter-area modes in uncertain conditions.

\section{References}

[1] “Global Wind Statistics 2017," Global Wind Energy Council, 2018. [Online]. Available: http://gwec.net/wpcontent/uploads/vip/GWEC_PRstats2017_EN003_FINAL.pdf. [Accessed: 14-Mar-2018].

[2] International Energy Agency, "Large-scale electricity interconnection - Technology and prospects for crossregional networks," 2016.

[3] "Interconnectors," 4C Offshore, 2018. [Online]. Available:https://www.4coffshore.com/transmission/inte rconnectors.aspx. [Accessed: 07-Aug-2018].

[4] M. R. Shah, J. Sanchez, R. Preece, and M. Barnes, "Stability and Control of Mixed AC-DC Systems with VSC-HVDC: A Review," IET Gener. Transm. Distrib., pp. 1-15, Jan. 2018.

[5] H. Wang and W. Du, Analysis and Damping Control of Power System Low-frequency Oscillations. Boston, MA: Springer US, 2016.

[6] A. Brandstädt, V. B. Le, and J. P. Spinrad, Graph Classes: A Survey. Society for Industrial and Applied Mathematics, 1999.

[7] E. Estrada, Graph and Network Theory in Physics. University of Strathclyde, 2013.
[8] R. Diestel, Graph Theory, vol. 2nd ed, no. Vol. 173. New York: Springer Science \& Business Media, 2000.

[9] K. R. W. Bell and A. N. D. Tleis, "Test system requirements for modelling future power systems," in IEEE PES General Meeting, 2010, pp. 1-8.

[10] "Electricity Ten Year Statement (ETYS)," National Grid. [Online]. Available:

https://www.nationalgrid.com/uk/publications/electricity -ten-year-statement-etys. [Accessed: 13-Mar-2018].

[11] "Transmission network use of system (TNUoS)," Natinal Grid UK. [Online]. Available: https://www.nationalgrid.com/uk/electricity/chargingand-methodology/transmission-network-use-systemtnuos-charges. [Accessed: 12-Mar-2018].

[12] R. D. Zimmerman and C. E. Murillo-s, "MATPOWER 6.0 User's Manual," 2016. [Online]. Available: http://www.pserc.cornell.edu/matpower/manual.pdf. [Accessed: 05-Jun-2018].

[13] P. M. Anderson and A. A. Fouad, POWER SYSTEM CONTROL AND STABILITY, 2ND ED. Wiley India Pvt. Limited, 2008.

[14] Department of Business Energy and Industrial Strategy, "BEIS Electricity Generation Costs," 2016.

[15] PES, IEEE Recommended Practice for Excitation System Models for Power System Stability Studies, vol. 2005, no. April. 2006.

[16] IEEE Power \& Energy Society, "Dynamic Models for Turbine-Governors in Power System Studies," 2013.

[17] P. Pourbeik et al., "Generic stability models for type 3 \& 4ind turbine generators for WECC," in 2013 IEEE Power \& Energy Society General Meeting, 2013, pp. 15.

[18] S. Lindenberg, B. Smith, K. O’Dell, and E. DeMeo, “20 Percent Wind Energy by 2030: Increasing Wind Energy's Contribution to U.S. Electricity Supply," 2008.

[19] Y. Chen, J. Fuller, R. Diao, N. Zhou, Z. Huang, and F. Tuffner, "The influence of topology changes on interarea oscillation modes and mode shapes," in 2011 IEEE Power and Energy Society General Meeting, 2011, no. 1, pp. 1-7.

[20] P. Hines, S. Blumsack, E. C. Sanchez, and C. Barrows, "The Topological and Electrical Structure of Power Grids," in 2010 43rd Hawaii International Conference on System Sciences, 2010, pp. 1-10.

[21] H. W. I. Cover, "NETWORK ADMITTANCE AND IMPEDANCE MATRICES," National Programme on Technology Enchanced Learning (NPTEL). [Online]. Available: https://nptel.ac.in/courses/117104071/chap3.pdf. [Accessed: 06-May-2018].

[22] S. de Siqueira Santos, D. Y. Takahashi, A. Nakata, and A. Fujita, "A comparative study of statistical methods used to identify dependencies between gene expression signals," Brief. Bioinform., vol. 15, no. 6, pp. 906-918, Nov. 2014.

[23] K. F. Weaver, V. Morales, S. L. Dunn, K. Godde, and P. F. Weaver, An Introduction to Statistical Analysis in Research. Hoboken, NJ, USA: John Wiley \& Sons, Inc., 2017. 


\section{Appendix}

The process of steady state modelling is illustrated in the

Figure A.1. The procedure is explained in detail in section

2.1.

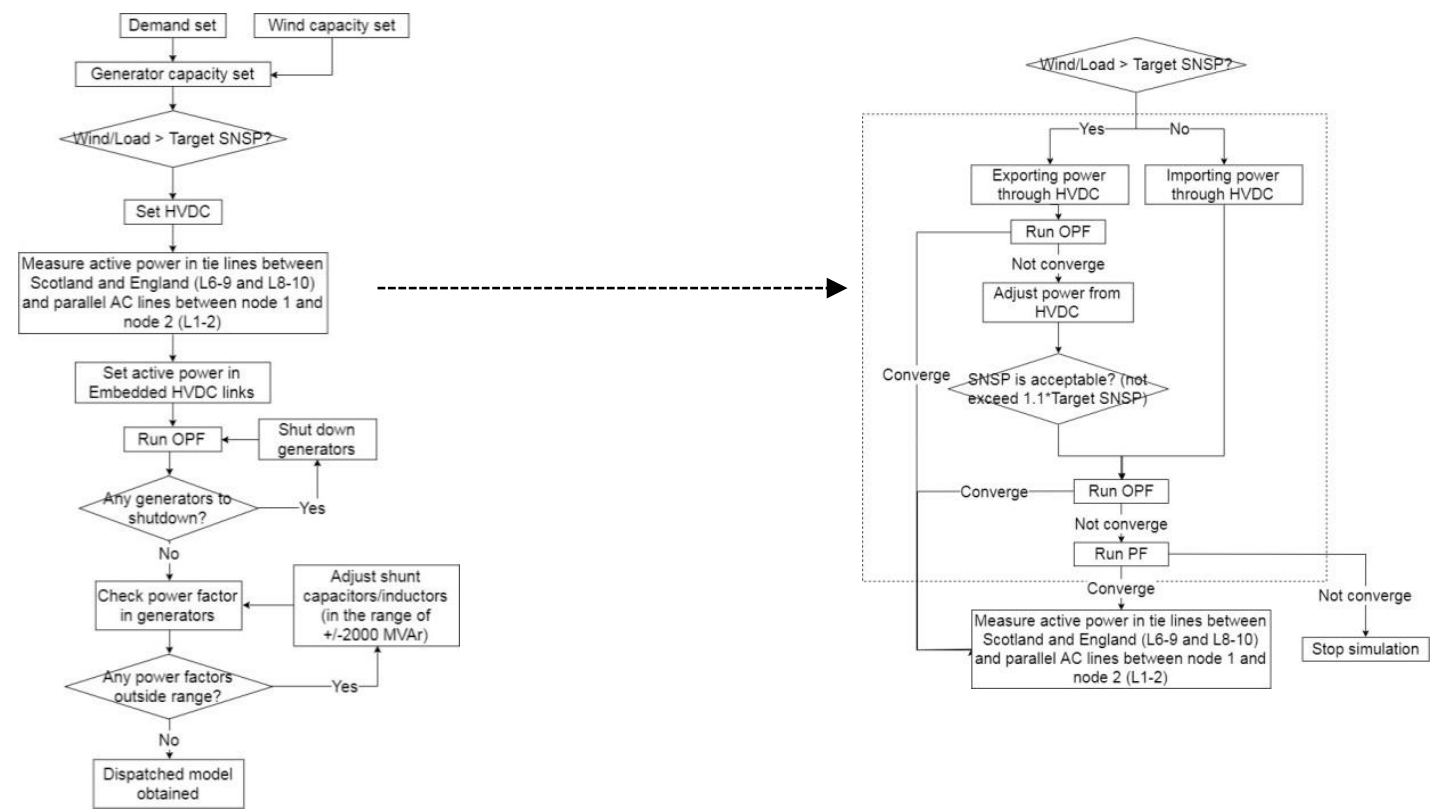

Figure A.1: Flow chart showing the calculation of steady state operating condition

\begin{tabular}{|c|c|c|c|c|}
\hline Bus No. & $\begin{array}{l}\text { Generation } \\
\text { Type }\end{array}$ & AVR Type & Governor Type & $\begin{array}{c}\text { Installed Capacity } \\
\text { in } 2030 \text { (MVA) }\end{array}$ \\
\hline \multirow{2}{*}{1} & Hydro & DC1A & HYGOV & 2053 \\
\hline & Wind & & & 4673 \\
\hline \multirow{2}{*}{2} & CCGT & DC1A & GAST & 400 \\
\hline & Wind & & & 1404 \\
\hline \multirow{2}{*}{3} & Hydro & DC1A & HYGOV & 956 \\
\hline & Wind & & & 3665 \\
\hline \multirow{2}{*}{5} & Nuclear & ST1A & TGOV1 & 947 \\
\hline & Wind & & & 606 \\
\hline 6 & Wind & & & 3937 \\
\hline \multirow{3}{*}{7} & CCGT & $\mathrm{DC} 1 \mathrm{~A}$ & GAST & 205 \\
\hline & Nuclear & ST1A & TGOV1 & 1216 \\
\hline & Wind & & & 1131 \\
\hline 8 & Wind & & & 254 \\
\hline 9 & Wind & & & 747 \\
\hline \multirow{3}{*}{10} & CCGT & DC1A & GAST & 426 \\
\hline & Nuclear & ST1A & TGOV1 & 1208 \\
\hline & Wind & & & 4000 \\
\hline \multirow{3}{*}{11} & CCGT & DC1A & GAST & 155 \\
\hline & Nuclear & ST1A & TGOV1 & 5793 \\
\hline & Wind & & & 1646 \\
\hline \multirow{4}{*}{12} & CCGT & DC1A & GAST & 1380 \\
\hline & Hydro & DC1A & HYGOV & 2083 \\
\hline & Nuclear & ST1A & TGOV1 & 2800 \\
\hline & Wind & & & 1574 \\
\hline \multirow{2}{*}{13} & CCGT & DC1A & GAST & 3882 \\
\hline & Wind & & & 254 \\
\hline 14 & CCGT & DC1A & GAST & 1280 \\
\hline \multirow{2}{*}{15} & CCGT & DC1A & GAST & 3405 \\
\hline & Coal & DC1A & TGOV1 & 1926 \\
\hline
\end{tabular}

\begin{tabular}{|c|c|c|c|c|}
\hline Bus No. & $\begin{array}{l}\text { Generation } \\
\text { Type }\end{array}$ & AVR Type & Governor Type & $\begin{array}{l}\text { Installed Capacity } \\
\text { in } 2030 \text { (MVA) }\end{array}$ \\
\hline \multirow{2}{*}{16} & CCGT & $\mathrm{DC} 1 \mathrm{~A}$ & GAST & 9941 \\
\hline & Wind & & & 4657 \\
\hline 17 & Coal & DC1A & TGOV1 & 1988 \\
\hline 18 & Nuclear & ST1A & TGOV1 & 2800 \\
\hline \multirow{2}{*}{19} & CCGT & DC1A & GAST & 3980 \\
\hline & Wind & & & 1721 \\
\hline \multirow{4}{*}{20} & CCGT & DC1A & GAST & 405 \\
\hline & Nuclear & ST1A & TGOV1 & 4556 \\
\hline & OCGT & DC1A & GAST & 299 \\
\hline & Wind & & & 8850 \\
\hline 22 & CCGT & DC1A & GAST & 740 \\
\hline \multirow{4}{*}{23} & CCGT & DC1A & GAST & 6238 \\
\hline & Hydro & DC1A & HYGOV & 320 \\
\hline & OCGT & DC1A & GAST & 299 \\
\hline & Wind & & & 228 \\
\hline 24 & CCGT & DC1A & GAST & 1550 \\
\hline \multirow{2}{*}{25} & CCGT & DC1A & GAST & 3208 \\
\hline & OCGT & DC1A & GAST & 144 \\
\hline \multirow{2}{*}{26} & CCGT & DC1A & GAST & 3790 \\
\hline & Nuclear & ST1A & TGOV1 & 1670 \\
\hline \multirow{2}{*}{27} & Nuclear & ST1A & TGOV1 & 1080 \\
\hline & Wind & & & 930 \\
\hline \multirow{3}{*}{28} & CCGT & DC1A & GAST & 1478 \\
\hline & OCGT & $\mathrm{DC} 1 \mathrm{~A}$ & GAST & 100 \\
\hline & Wind & & & 400 \\
\hline \multirow{3}{*}{29} & CCGT & DC1A & GAST & 905 \\
\hline & Nuclear & ST1A & TGOV1 & 4252 \\
\hline & OCGT & DC1A & GAST & 140 \\
\hline
\end{tabular}

Table A.2: Total installed generation capacity and types of AVR and Governor for generators in the GB system 